\title{
(6) OPEN ACCESS \\ Ocular hypotensive effect of the novel EP3/FP agonist ONO-9054 versus Xalatan: results of a 28-day, double-masked, randomised study
}

\author{
Eydie Miller Ellis, ${ }^{1}$ Michael S Berlin, ${ }^{2}$ Caroline L Ward ${ }^{3}$ John A Sharpe, ${ }^{3}$ Alam Jamil, ${ }^{3}$ \\ Alon Harris ${ }^{4}$
}

${ }^{1}$ Perelman School of Medicine at the University of Pennsylvania, Philadelphia, Pennsylvania, USA ${ }^{2}$ Glaucoma Institute of Beverly Hills \& Jules Stein Eye Institute, UCLA, Los Angeles, California, USA

${ }^{3}$ Ono Pharma UK, London, UK ${ }^{4}$ Eugene and Marilyn Glick Eye Institute, Indiana University School of Medicine, Indianapolis, Indiana, USA

Correspondence to Dr Eydie Miller Ellis, Perelman School of Medicine at the University of Pennsylvania, Philadelphia, Pennsylvania, USA; Eydie.Miller@uphs.upenn.edu

Received 12 May 2016 Revised 4 August 2016 Accepted 10 August 2016 Published Online First 20 September 2016

CrossMark

To cite: Miller Ellis $\mathrm{E}$, Berlin MS, Ward CL, et al. Br J Ophthalmol 2017:101:796-800.

\section{ABSTRACT}

Background/aims ONO-9054 is being developed for the reduction of intraocular pressure (IOP) in patients with ocular hypertension (OHT) and open-angle glaucoma (OAG). This study compared the novel dual EP3/FP agonist ONO-9054 with the FP agonist Xalatan. Methods Adults $(n=123)$ with bilateral mild/moderate OAG or OHT, with unmedicated IOP of $\geq 24 \mathrm{~mm} \mathrm{Hg}$ at 8:00 hours, $\geq 21 \mathrm{~mm} \mathrm{Hg}$ at 10:00 hours and $\leq 36 \mathrm{~mm} \mathrm{Hg}$, were randomised 1:1 to receive ONO-9054 $(0.003 \%, 30 \mu \mathrm{g} / \mathrm{mL})$ or Xalatan $(0.005 \%, 50 \mu \mathrm{g} / \mathrm{mL})$ once daily for 28 days.

Results Day 29 mean diurnal IOP was $-7.2 \mathrm{~mm} \mathrm{Hg}$ for ONO-9054 vs $-6.6 \mathrm{~mm} \mathrm{Hg}$ for Xalatan. At

08:00 hours, the IOPs were comparable, and at all later time points the decrease in IOP was greater for ONO9054. On day 29 , the odds of a mean IOP reduction of $\leq-25 \%, \leq-30 \%$ and $\leq-35 \%$ for ONO-9054 were $2.39,2.37$ and 4.85 times more, respectively, than the odds for Xalatan ( $p<0.05$, post hoc analyses). The percentage of subjects achieving target IOPs on day 29 $(\leq 17, \leq 16$ and $\leq 15 \mathrm{~mm} \mathrm{Hg}$ ) was greater for ONO9054 than for Xalatan; the odds of achieving an IOP $\leq 15 \mathrm{~mm} \mathrm{Hg}$ for ONO-9054 were 2.4 times more than the odds for Xalatan ( $p<0.01$, post hoc analysis).

Conclusions Subjects randomised to receive ONO9054 were more likely to achieve a greater per cent reduction in IOP and were more likely to achieve target IOPs than those receiving Xalatan. The effects of ONO9054 in reducing IOP appear to persist longer than those of Xalatan.

Trial registration number NCT02083289, Results.

\section{INTRODUCTION}

Open-angle glaucoma (OAG), a chronic ocular disease characterised by progressive optic neuropathy and visual field loss, is the second most common cause of blindness. ${ }^{1}$ Elevated intraocular pressure (IOP) is a major risk factor for development and progression of OAG. Reduction of IOP prevents or delays onset of OAG in patients with ocular hypertension (OHT) ${ }^{2}$ and slows progression in both normal and elevated pressure OAG. ${ }^{3-7}$

Prostaglandin analogues (PGAs) are commonly prescribed IOP-lowering medications targeting the prostanoid $\mathrm{F}(\mathrm{FP})$ receptor which lower IOP mainly by increasing the outflow of aqueous humour, primarily through the uveoscleral pathway. ${ }^{8-10}$ ONO-9054 (sepetaprost) is a novel dual EP3 and FP agonist. ${ }^{11}$ In monkeys, more potent and longer lasting IOP-lowering effects are seen compared with existing PGAs; ${ }^{11}$ this reduction is via increase in trabecular and uveoscleral outflow. ${ }^{12}$ It was hypothesised that dual agonist activity might provide a greater and more sustained reduction in IOP.

ONO-9054 is safe and well tolerated in normotensive adults and in those with OHT and OAG at doses up to $30 \mu \mathrm{g} / \mathrm{mL}^{13-15}$ A single dose of ONO-9054 reduced IOP by up to $28.23 \%$ in normotensive, healthy adults. ${ }^{13}$ After 14 days of dosing in adults with OHT or OAG, the peak reduction in IOP was from 23.3 to $15.1 \mathrm{mmHg}$ at 1 hour post final dose with a sustained effect to at least 24 hours post final dose, with similar effects achieved from morning and evening dosing. ${ }^{13} 15$ The purpose of this study was to compare the EP3/ FP agonist ONO-9054 with the FP agonist Xalatan; this manuscript reports the results of this trial.

\section{MATERIALS AND METHODS \\ Subjects}

Men and women aged 18-85 years with a diagnosis of bilateral OHT or mild to moderate OAG; an unmedicated IOP $\geq 24 \mathrm{~mm} \mathrm{Hg}$ at 08:00 hours, $\geq 21 \mathrm{~mm} \mathrm{Hg}$ at $10: 00$ hours and $\leq 36 \mathrm{~mm} \mathrm{Hg}$; central corneal thickness of $500-620 \mu \mathrm{m}$; bestcorrected visual acuity (BCVA) of at least +0.7 LogMar and ocular cup-to-disc ratio $\leq 0.8$. Exclusion criteria included: a history of severe ocular trauma; a history of angle closure or current angle of $\leq 2$ (Shaffer scale); intraocular or ocular laser surgery within 3 months; refractive surgery within 6 months.

\section{Study design}

This phase II, randomised, double-masked, active comparator study took place between 02 June and 02 December 2015 at nine clinical sites in the USA (NCT02083289). The protocol was approved by institutional review boards (IRBs), and the study was conducted in accordance with the ethical principles of Good Clinical Practice and the Declaration of Helsinki. All subjects provided written, informed consent. Subjects were required to attend seven study visits (eligibility review 1 (ER1; day -45 to day -6$)$, eligibility review 2 (ER2; day $-5 \pm 2$ days), eligibility review 3 (day 1 , used as baseline), day 8 \pm 2 days, day $15 \pm 2$ days, day $29 \pm 2$ days and day 35 \pm 3 days (follow-up visit)).

Subjects were randomised 1:1 to ONO-9054 $30 \mu \mathrm{g} / \mathrm{mL} \quad(0.003 \%)$ or Xalatan $(0.005 \%)$ for 28 days by IWRS. Stratification was by site and baseline IOP (day 1, 08:00 hours) as either $<26$ or 
$\geq 26 \mathrm{~mm} \mathrm{Hg}$. Study drug was self-administered as one drop (approximately $30 \mu \mathrm{L}$ ) in each eye once daily at 22:00 \pm 2 hours. Xalatan was provided in the US commercial bottle, overlabelled to maintain the masking, and ONO-9054 was supplied in a polypropylene bottle with polyethylene nozzle and cap. Both were dispensed and stored in plastic containers to maintain masking.

\section{Pharmacodynamics}

IOP readings were performed using Goldmann applanation tonometry with masked observer and recorder. IOP was assessed on days 1, 8, 15 and 29 at 08:00, 10:00, 12:00, 16:00 hours and at 20:00 hours on days 1 and 29. A single IOP measurement was taken at an unspecified time on day 35.

\section{Safety and tolerability}

Vital signs, safety laboratory evaluations and concomitant medication data were recorded throughout the study; physical examinations were conducted throughout the study, and treatment-emergent adverse events (TEAEs) were recorded from days 1 to 35. Ocular safety assessment included BCVA, symptomatology, pupillometry and slit-lamp examinations, which were conducted at ER1 and days 1, 8, 15, 29 and 35. Pachymetry was measured at ER1, ER2 and days 29 and 35. Indirect ophthalmology examination was conducted at ER1, ER2 and days 15, 29 and 35. Optical coherence tomography images were captured at ER1 and on days 29 and 35 and read both by the investigator and a central reader. Hyperaemia was evaluated by comparison with standardised photographs (Ora Calibra Redness Scale 6.b (0-3 scale), used under licence from Ora, Andover, Massachusetts, USA)) on days 1, 8, 15, 29 and 35. Symptomatology (photophobia, itching, tearing, dryness and discharge as 0 (absent), 1 (mild), 2 (moderate), 3 (severe with stinging or burning) or 4 (severe with blurred or dim vision)) was assessed on days 1, 8, 15, 29 and 35 .

\section{Statistics}

The study was powered $(\geq 80 \%)$ to detect a difference between treatments at the $5 \%$ significance level. The power was estimated based on the assumption that the true treatment difference between ONO-9054 and Xalatan was not $<2.0 \mathrm{~mm} \mathrm{Hg}$ and the SD was no more than $3.5 \mathrm{~mm} \mathrm{Hg}$. The safety analysis set (SAF) included all subjects who received study medication and was used for analysis of safety data. The per protocol set (PPS) included all subjects who had no major protocol violation (determined prior to unmasking), compliance $>80 \%$, treatment duration $\geq 21$ days and IOP assessments on days 1 and 29; PPS was used for analysis of pharmacodynamic data.

Statistical output was generated using SAS V.9.2 (SAS, Cary, North Carolina, USA.). The primary analysis was mean change from baseline (CFB), where day 1 is baseline, in mean diurnal IOP on day 29 (08:00, 10:00, 12:00 and 16:00 hours) using both analysis of covariance with the mean baseline diurnal IOP for the four time points on day 1 and study site as covariates, and also by the Student's t-test. Diurnal IOP secondary endpoints were analysed for actual and percentage change using mixed model repeat measures. Post hoc analyses were conducted to better understand and interpret the data and support the prospective analyses; these used the same methods as prospective analyses. For IOP analyses, data from the eligible eye were used, defined as day $1 \mathrm{IOP} \geq 24 \mathrm{~mm} \mathrm{Hg}$ at 08:00 hours and $\geq 21 \mathrm{~mm} \mathrm{Hg}$ at 10:00 hours; when both were eligible, that with the higher IOP at 08:00 hours on day 1 was used, and if both had the same IOP at 08:00 hours on day 1, the right eye was the eligible eye.
The primary endpoint was change in mean diurnal IOP (average of 08:00, 10:00, 12:00 and 16:00 hours) on day 29. Secondary and post hoc analyses included comparisons of diurnal IOP at other combinations of time points, individual time points, per cent responders and treatment response rates to target IOPs.

\section{RESULTS}

\section{Disposition, demographics and baseline characteristics}

One hundred and twenty-three subjects were randomised (62 to ONO-9054 and 61 to Xalatan). The mean age was 64.5 years, and $54.5 \%$ of subjects were female. The population was $72.4 \%$ white, 25.2\% black or African-American and 2.4\% Asian. The demographic profile was similar in the two treatment groups. The majority of subjects $(56.1 \%)$ had not received any previous glaucoma medications, but in those that had, the incidence was similar between the groups. Approximately half the subjects had the right eye designated as the eligible eye (50.4\%), with the incidence of eligible right and left eyes being similar between the groups. More subjects had OAG than OHT $(68.3 \%$ vs $31.7 \%)$, and more ONO-9054 subjects had OHT compared with Xalatan (37.1\% vs $26.2 \%)$. The mean baseline IOP and number of subjects with baseline diurnal IOP $<26$ and $\geq 26 \mathrm{~mm} \mathrm{Hg}$ were similar between groups.

One subject from the ONO-9054 group withdrew due to AEs of moderate conjunctival hyperaemia (considered definitely related to treatment) starting 2 days after the start of treatment, and mild discomfort with blinking (considered probably related to treatment) starting 3 days after the start of treatment. One subject from the Xalatan group was withdrawn by the site after 22 days of treatment because blood for safety analyses could not be obtained. More ONO-9054 subjects were excluded from the PPS (14.5\%) compared with that of Xalatan (4.9\%), with more ONO-9054 subjects excluded due to compliance issues $(6.5 \%$ for ONO-9054 vs 0\% for Xalatan).

\section{Pharmacodynamics}

Both groups showed decreases in diurnal IOP from day 8 (the first on-treatment assessment), which were maintained throughout the dosing period (figure 1 and table 1). ONO-9054 achieved a greater reduction in mean diurnal IOP (08:00, 10:00, 12:00 and $16: 00$ hours; $-7.2 \mathrm{~mm} \mathrm{Hg}$ vs $-6.6 \mathrm{~mm} \mathrm{Hg}$ ) compared with Xalatan, but this was not statistically significant at the $5 \%$ level. Mean CFB in IOP for ONO-9054 was numerically superior to that for Xalatan at all time points, with IOPs comparable at 08:00 hours and a greater decrease in IOP for ONO-9054 compared with that for Xalatan later in the day (figure 1 inset and table 1). Statistical significance was achieved at some individual time points and also for day 29 at 10:00, 12:00, 16:00 and 20:00 hours combined ( $p<0.05$, post hoc analysis). SDs for ONO-9054 data were generally higher than those for Xalatan.

ONO-9054 subjects were more likely to achieve a greater response to treatment (figure 2). On day 29, the odds of a mean IOP reduction of $\leq-25 \%, \leq-30 \%$ and $\leq-35 \%$ for ONO-9054 were $2.39,2.37$ and 4.85 times more, respectively, than the odds for Xalatan $(\mathrm{p}<0.05$, post hoc analyses). The odds of an IOP reduction of $\leq-30 \%$ and $\leq-40 \%$ for ONO-9054 subjects were 1.9 and 2.4 times more, respectively, than the odds for Xalatan across all time points from days 8, 15 and 29 combined $(\mathrm{p}<0.001$, post hoc analyses). The percentage of subjects achieving target IOP on day $29(\leq 17, \leq 16$ and $\leq 15 \mathrm{~mm} \mathrm{Hg})$ was greater for ONO-9054 than that for Xalatan (table 2), and the odds of achieving a target IOP $\leq 15 \mathrm{~mm} \mathrm{Hg}$ for ONO-9054 were 
Figure 1 Time-matched change from baseline for mean intraocular pressure (IOP) $(\mathrm{mm} \mathrm{Hg})$ following 8, 14 and 28 consecutive days of dosing for subjects receiving 0NO-9054 $30 \mu \mathrm{g} / \mathrm{mL}$ or Xalatan $10 \mu \mathrm{g} / \mathrm{mL}( \pm S D)$. Subjects receiving 0N0-9054 achieved a greater reduction in IOP at all time points. Inset: Mean IOP (mm Hg) for subjects receiving 0N0-9054 $30 \mu \mathrm{g} / \mathrm{mL}$ or Xalatan $10 \mu \mathrm{g} / \mathrm{mL}( \pm \mathrm{SD})$ following 28 consecutive days of dosing. Subjects receiving 0N0-9054 displayed a similar reduction in IOP at 08:00 hours and a greater reduction in IOP at all other time points suggesting a more sustained response. ${ }^{*} \mathrm{p}<0.05(10: 00$, $12: 00,16: 00,20: 00$ hours post hoc analysis).

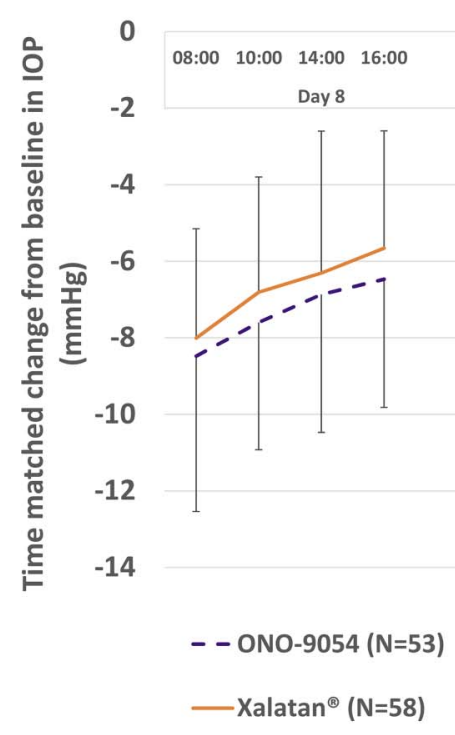

Day/Time point

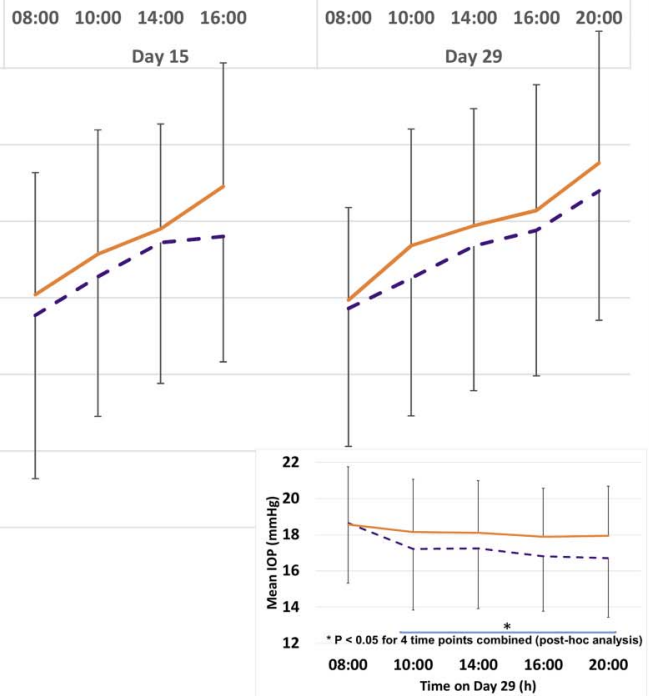

Table 1 Diurnal and mean diurnal (08:00, 10:00, 12:00, and 16:00 hours) IOP ( $\mathrm{mm} \mathrm{Hg}$ ) and change from baseline for time-matched time points in study eye (PPS)

\begin{tabular}{|c|c|c|c|c|c|c|c|}
\hline \multirow[b]{2}{*}{ Day } & \multirow[b]{2}{*}{ Time } & \multicolumn{3}{|l|}{ ONO-9054 (N=53) } & \multicolumn{3}{|l|}{ Xalatan $(\mathrm{N}=58)$} \\
\hline & & $\begin{array}{l}\text { Observed value, } \\
\mathrm{mm} \mathrm{Hg}\end{array}$ & $\begin{array}{l}\text { Change from } \\
\text { baseline, } \mathrm{mm} \mathrm{Hg}\end{array}$ & $\begin{array}{l}\% \text { Change from } \\
\text { baseline }\end{array}$ & $\begin{array}{l}\text { Observed value, } \\
\mathrm{mm} \mathrm{Hg}\end{array}$ & $\begin{array}{l}\text { Change from } \\
\text { baseline, } \mathrm{mm} \mathrm{Hg}\end{array}$ & $\begin{array}{l}\% \text { Change from } \\
\text { baseline }\end{array}$ \\
\hline $\begin{array}{l}\text { Day } 1 \\
\text { baseline }\end{array}$ & $\begin{array}{l}08: 00 \\
10: 00 \\
12: 00 \\
16: 00 \\
20: 00\end{array}$ & $\begin{array}{l}26.9(3.2) \\
24.7(2.8) \\
23.9(3.1) \\
23.1(3.2) \\
21.9(3.6)\end{array}$ & & & $\begin{array}{l}26.6(2.5) \\
24.8(2.8) \\
24.2(3.1) \\
23.6(3.6) \\
22.4(3.4)\end{array}$ & & \\
\hline $\begin{array}{l}\text { Mean diurnal } \\
\text { IOP }\end{array}$ & & $24.6(2.4)$ & & & $24.8(2.6)$ & & \\
\hline Day 8 & $\begin{array}{l}08: 00 \\
10: 00 \\
12: 00 \\
16: 00\end{array}$ & $\begin{array}{l}18.5(3.4) \\
17.1(3.2) \\
17.0(3.4) \\
16.6(2.9)\end{array}$ & $\begin{array}{l}-8.5(4.1) \\
-7.6(3.3) \\
-6.9(3.6) \\
-6.5(3.4)\end{array}$ & $\begin{array}{l}-31.0(13.1) \\
-30.5(12.2) \\
-28.3(13.5) \\
-27.3(12.8)\end{array}$ & $\begin{array}{l}18.6(3.1) \\
18.0(3.2) \\
17.9(2.8) \\
18.0(3.1)\end{array}$ & $\begin{array}{l}-8.0(2.9) \\
-6.8(3.0) \\
-6.3(3.7) \\
-5.7(3.1)\end{array}$ & $\begin{array}{l}-30.0(10.0) \\
-27.3(11.2) \\
-25.3(13.1) \\
-23.3(11.7)\end{array}$ \\
\hline $\begin{array}{l}\text { Mean diurnal } \\
\text { IOP }\end{array}$ & & $17.3(2.9)$ & $-7.4(2.9)$ & $-29.7(10.7)$ & $18.1(2.7)$ & $-6.7(2.5)$ & $-26.8(9.0)$ \\
\hline Day 15 & $\begin{array}{l}08: 00 \\
10: 00 \\
12: 00 \\
16: 00\end{array}$ & $\begin{array}{l}18.5(3.6) \\
17.3(3.4) \\
17.3(3.8) \\
16.7(2.9)\end{array}$ & $\begin{array}{l}-8.5(4.3) \\
-7.5(3.7) \\
-6.6(3.7) \\
-6.4(3.3)\end{array}$ & $\begin{array}{l}-30.9(13.9) \\
-29.8(13.6) \\
-27.2(13.7) \\
-27.1(12.4)\end{array}$ & $\begin{array}{l}18.7(3.4) \\
17.9(2.8) \\
18.0(2.4) \\
18.5(2.8)\end{array}$ & $\begin{array}{l}-7.9(3.2) \\
-6.9(3.2) \\
-6.2(2.7) \\
-5.1(3.2)\end{array}$ & $\begin{array}{l}-29.7(11.3) \\
-27.2(11.5) \\
-25.1(9.2) \\
-20.7(12.0)\end{array}$ \\
\hline $\begin{array}{l}\text { Mean diurnal } \\
\text { IOP }\end{array}$ & & $17.4(3.1)$ & $-7.2(3.0)$ & $-29.2(11.2)$ & $18.3(2.4)$ & $-6.5(2.4)$ & $-26.0(8.4)$ \\
\hline Day 29 & $\begin{array}{l}08: 00 \\
10: 00 \\
12: 00 \\
16: 00 \\
20: 00\end{array}$ & $\begin{array}{l}18.7(3.3) \\
17.2(3.4) \\
17.3(3.3) \\
16.8(3.0) \\
16.7(3.3)\end{array}$ & $\begin{array}{l}-8.3(3.6) \\
-7.5(3.6) \\
-6.7(3.8) \\
-6.2(3.8) \\
-5.2(3.4)\end{array}$ & $\begin{array}{l}-30.4(11.3) \\
-30.0(13.4) \\
-27.2(14.1) \\
-26.1(14.8) \\
-23.2(12.1)\end{array}$ & $\begin{array}{l}18.6(3.2) \\
18.2(2.9) \\
18.1(2.9) \\
17.9(2.7) \\
17.9(2.8)\end{array}$ & $\begin{array}{l}-8.1(2.4) \\
-6.6(3.0) \\
-6.1(3.1) \\
-5.7(3.3) \\
-4.5(3.4)\end{array}$ & $\begin{array}{l}-30.4(8.9) \\
-26.5(10.9) \\
-24.8(11.0) \\
-23.3(12.0) \\
-19.0(13.0)\end{array}$ \\
\hline $\begin{array}{l}\text { Mean diurnal } \\
\text { IOP }\end{array}$ & & $17.5(2.9)$ & $-7.2(3.1)$ & $-28.8(11.4)$ & $18.2(2.5)$ & $-6.6(2.0)$ & $-26.7(7.3)$ \\
\hline $\begin{array}{l}\text { Day } 35 \\
\text { follow-up }\end{array}$ & & $23.3(3.8)$ & & & $23.1(4.2)$ & & \\
\hline
\end{tabular}

2.4 times more than the odds for Xalatan $(\mathrm{p}<0.01$, post hoc analysis; $\leq 17$ and $\leq 16$ analyses not performed).

\section{Safety and tolerability}

There were 37 AEs in 22 ONO-9054 subjects and 35 AEs in 18 Xalatan subjects (table 3); all were mild or moderate in intensity. The most common system organ class (SOC) was eye disorders, with the incidence of TEAEs in this SOC being higher for ONO-9054 compared with that for Xalatan (31 events compared with 25). The most common TEAE was conjunctival hyperaemia. One unrelated serious adverse event (non-arteritic ischaemic optic neuropathy, reported on day 28) occurred in a subject randomised to receive ONO-9054. 


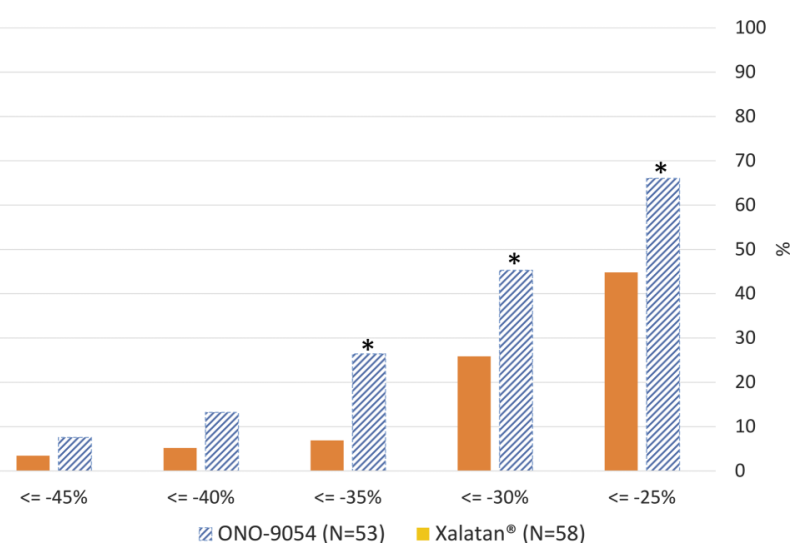

Figure 2 Per cent change from baseline in diurnal intraocular pressure (IOP) at day 29 (08:00, 10:00. 12:00, 16:00 and 20:00 hours) for ONO-9054 and Xalatan. The odds of a mean IOP reduction of $\leq-25 \%, \leq-30 \%$ and $\leq-35 \%$ for ONO-9054 were 2.39, 2.37 and 4.85 times more, respectively, than the odds for Xalatan $(p<0.05$, post hoc analyses). The odds of an IOP reduction of $\leq-30 \%$ and $\leq-40 \%$ for 0N0-9054 subjects were 1.9 and 2.4 times more, respectively, than the odds for Xalatan across all time points from days 8, 15 and 29 combined ( ${ }^{*} p<0.001$, post hoc analyses).

Hyperaemia scores and CFB were similar between ONO-9054 and Xalatan groups (mean (minimum, maximum) CFB at day 29 was $0.19(-1.00,2.50)$ for ONO-9054 vs 0.21 $(-0.50,1.00)$ for Xalatan); however, the number of hyperaemia adverse events (AEs) for ONO-9054 was higher than that for Xalatan (19.4\% of ONO-9054 vs $8.2 \%$ of Xalatan subjects). Hyperaemia AEs resolved without sequelae, and symptoms returned to baseline levels by follow-up. Symptomatology scores were similar between treatment groups at baseline, and most subjects showed no change in scores during the study.

No notable differences were seen between treatment groups for vital signs, laboratory or ocular safety parameters, and no observations were seen that were indicative of a harmful ocular effect occurring with either treatment.

\section{DISCUSSION}

The purpose of this investigation was to compare the EP3/FP agonist ONO-9054 with the FP agonist Xalatan. Xalatan was selected as the comparator since there is evidence that Xalatan reduces IOP more than the generic latanoprost ${ }^{16} 17$ and thus represents the most appropriate and significant comparative standard. In addition, as multiple generic brands of latanoprost are available, Xalatan was used to allow consistency of comparison.
Slightly more subjects with OHT were randomised to ONO-9054 compared with Xalatan; the significance with respect to response to treatment is unclear. During the masked data review, a greater number of ONO-9054 subjects were excluded from PPS due to low compliance, as measured by a paper diary. ONO-9054 and ONO-AG-367 are cleared from plasma rapidly; so, there would have been no measurable levels following the evening dosing. Potentially, ease of use of the different shaped bottles could have impacted dosing compliance.

The CFB in mean diurnal IOP (average of 08:00, 10:00, 12:00 and 16:00 hours) was greater for ONO-9054 $(-7.2 \mathrm{~mm} \mathrm{Hg})$ compared with that for Xalatan $(-6.6 \mathrm{~mm} \mathrm{Hg})$. The reduction in IOP for Xalatan was within the wide range of values previously reported for latanoprost, ${ }^{17-22}$ although direct comparison between studies is challenging due to differing dosing durations, IOP measurement times, inclusion and exclusion criteria and baseline IOP. In addition, it is not always clear whether data for Xalatan or for generic latanoprost are being reported.

These data suggest that following evening dosing, both treatments were similarly effective at 08:00 hours, but there was a greater and more prolonged effect for ONO-9054 compared with that for Xalatan throughout the day. The observed sustained response was predicted from preclinical and clinical data $^{11} 13 \quad 15$ however, considering the rapid clearance from plasma of the active metabolite ONO-AG-367, ${ }^{13}$ the mechanism for this sustained response is unknown. Nonetheless, this sustained reduction of IOP may be beneficial for subjects with OAG and OHT.

Subjects with higher baseline IOP have previously been shown to respond better to PGAs; ${ }^{18}$ therefore, baseline IOP was used both as a stratification factor and a covariate in analyses to avoid bias. However, in this study, there was no evidence of a greater treatment difference for ONO-9054 versus Xalatan in subjects with a higher baseline IOP.

ONO-9054 subjects had a greater response to treatment, with more ONO-9054 subjects having a reduction in IOP of $\leq-25 \%$, $\leq-30 \%, \leq-35 \%$ and $\leq-40 \%$ from baseline and achieving an absolute IOP value $\leq 17,16$ and $15 \mathrm{~mm} \mathrm{Hg}$. Reduction in IOP is a recognised goal in the treatment of OAG and OHT and correlates with long-term outcomes in glaucoma; ${ }^{3-7}$ therefore, it is considered that there is a potential clinical benefit from treatment with ONO-9054, particularly in patients with a high risk of progression requiring a large initial reduction in IOP. Since the extent of reduction in IOP was evident from the first IOP measurement day, it is possible to identify responders and nonresponders rapidly even in the absence of a method to predict response. There was a greater range of responses to ONO-9054 than to Xalatan, with some subjects $(\sim 10 \%)$ being low

Table 2 Number and per cent of subjects achieving a target IOP of $\leq 17, \leq 16$ and $\leq 15 \mathrm{~mm} \mathrm{Hg}$ on day 29 (PPS)

\begin{tabular}{|c|c|c|c|c|c|c|}
\hline \multirow[b]{2}{*}{ Target IOP, mm Hg } & & \multicolumn{5}{|c|}{ Number (per cent) of subjects achieving target response } \\
\hline & & 08:00 & $10: 00$ & $12: 00$ & $16: 00$ & $20: 00$ \\
\hline \multirow[t]{2}{*}{$\leq 17$} & ONO-9054 & $21(39.6)$ & $29(54.7)$ & $26(49.1)$ & $33(62.3)$ & $31(58.5)$ \\
\hline & Xalatan & $23(39.7)$ & $24(41.4)$ & 27 (46.6) & $31(53.4)$ & $24(41.4)$ \\
\hline \multirow[t]{2}{*}{$\leq 16$} & ONO-9054 & $14(26.4)$ & $23(43.4)$ & 21 (39.6) & $25(47.2)$ & $27(50.9)$ \\
\hline & Xalatan & $15(25.9)$ & $17(29.3)$ & $17(29.3)$ & $17(29.3)$ & 16 (27.6) \\
\hline \multirow[t]{2}{*}{$\leq 15^{*}$} & ONO-9054 & 7 (13.2) & $17(32.1)$ & $17(32.1)$ & $18(34.0)$ & $22(41.5)$ \\
\hline & Xalatan & $7(12.1)$ & $9(15.5)$ & $10(17.2)$ & $6(10.3)$ & $10(17.2)$ \\
\hline
\end{tabular}


Table 3 Treatment emergent adverse events (TEAEs) reported by $>1$ subject

\begin{tabular}{|c|c|c|c|c|}
\hline \multirow{2}{*}{$\begin{array}{l}\text { System organ class } \\
\text { preferred term }\end{array}$} & \multicolumn{2}{|c|}{$\begin{array}{l}\text { ONO-9054 } \\
30 \mu \mathrm{g} / \mathrm{mL}(0.003 \%) \\
(\mathrm{N}=62)\end{array}$} & \multicolumn{2}{|c|}{$\begin{array}{l}\text { Xalatan } 0.005 \% \\
(\mathrm{~N}=61)\end{array}$} \\
\hline & Events & Subjects (\%) & Events & Subjects (\%) \\
\hline Total number of TEAEs & 37 & $22(35.5)$ & 35 & $18(29.5)$ \\
\hline Eye disorders & 31 & $21(33.9)$ & 25 & $14(23.0)$ \\
\hline Conjunctival hyperaemia & 14 & $12(19.4)$ & 5 & $5(8.2)$ \\
\hline Vision blurred & 3 & $3(4.8)$ & 0 & 0 \\
\hline Abnormal sensation in eye & 2 & $2(3.2)$ & 2 & $2(3.3)$ \\
\hline Visual acuity reduced & 2 & $2(3.2)$ & 1 & $1(1.6)$ \\
\hline Punctate keratitis & 2 & $2(3.2)$ & 3 & $3(4.9)$ \\
\hline Dry eye & 1 & $1(1.6)$ & 2 & $2(3.3)$ \\
\hline Eye discharge & 1 & $1(1.6)$ & 3 & $2(3.3)$ \\
\hline Eye pruritus & 0 & 0 & 2 & $2(3.3)$ \\
\hline Episcleral hyperaemia & 0 & 0 & 2 & $2(3.3)$ \\
\hline $\begin{array}{l}\text { General disorders and } \\
\text { administrative site conditions }\end{array}$ & 2 & $2(3.2)$ & 6 & $6(9.8)$ \\
\hline Instillation site pain & 2 & $2(3.2)$ & 5 & $5(8.2)$ \\
\hline Infections and infestations & 1 & $1(1.6)$ & 4 & $3(4.9)$ \\
\hline Nasopharyngitis & 0 & 0 & 2 & $2(3.3)$ \\
\hline
\end{tabular}

responders to ONO-9054, while others were very high responders. There is currently no explanation for this; although, interestingly, low responders to ONO-9054 had no increases from baseline in hyperaemia score, which may indicate low compliance.

Although the hyperaemia scores were similar in both groups, the incidence of hyperaemia AEs was higher in the ONO-9054 group. The reporting of hyperaemia as an $\mathrm{AE}$ was inconsistent across sites and did not correlate to either the hyperaemia score or $\mathrm{CFB}$, making these $\mathrm{AE}$ data difficult to interpret.

\section{CONCLUSION}

ONO-9054 and Xalatan were both safe and well tolerated. ONO-9054 subjects were more likely to achieve a significantly greater per cent reduction in IOP than those receiving Xalatan and were more likely to achieve target IOPs. Additionally, the effects of ONO-9054 in reducing IOP appear to persist longer than those of Xalatan; however, further study is required. This study supports further development of ONO-9054 for treatment of OAG and OHT.

\section{Acknowledgements The authors would like to thank the study participants, investigators and site staff, Dr Robert David the medical monitor and the team at Ora. The authors would also like to thank Osamu Ito, Takayuki Iwata, Chris Powell and the study team from Ono Pharma UK for all of their hard work on this study, and the members of the ONO-9054 global project team located at Ono Pharma USA and Ono Pharmaceutical Co, Japan.}

Contributors All authors contributed to the conception and/or design of the study and/or acquisition, analysis and interpretation of the data. All authors critically revised the content of this manuscript and have approved this final version for publication. All authors are accountable for all aspects of the work in relation to the accuracy and integrity of the scientific content.

Funding This study was funded by ONO Pharmaceuticals Co, Osaka, Japan.

Competing interests CLW, JAS and AJ conducted this work as paid employees of ONO Pharma UK. EME, MSB and AH acted as consultants and were remunerated for their work by ONO Pharmaceuticals Co.

Ethics approval IRBs for each of the sites approved the study.

Provenance and peer review Not commissioned; externally peer reviewed.
Data sharing statement The main data from this study are presented in this manuscript. Ono Pharma does not plan to share any other data from this study at this time.

Open Access This is an Open Access article distributed in accordance with the Creative Commons Attribution Non Commercial (CC BY-NC 4.0) license, which permits others to distribute, remix, adapt, build upon this work non-commercially, and license their derivative works on different terms, provided the original work is properly cited and the use is non-commercial. See: http://creativecommons.org/ licenses/by-nc/4.0/

\section{REFERENCES}

1 Quigley HA, Broman AT. The number of people with glaucoma worldwide in 2010 and 2020. Br J Ophthalmology 2006;90:262-7.

2 Kass MA, Heuer DK, Higginbotham EJ, et al. The ocular hypertension treatment study: a randomized trial determines that topical ocular hypotensive medication delays or prevents the onset of primary open-angle glaucoma. Arch Ophthalmol 2002;120:701-13; discussion 829-30.

3 Leske MC, Heijl A, Hyman L, et al. Predictors of long-term progression in the early manifest glaucoma trial. Ophthalmology 2007;114:1965-72.

4 Leske MC, Heijl A, Hussein M, et al. Factors for glaucoma progression and the effect of treatment: the Early Manifest Glaucoma Trial. Arch Ophthalmol 2003;121:48-56.

5 The Advanced Glaucoma Intervention Study (AGIS): 7. The relationship between control of intraocular pressure and visual field deterioration. The AGIS Investigators. Am I Ophthalmol 2000;130:429-40.

6 Heijl A, Leske MC, Bengtsson B, et al. Reduction of intraocular pressure and glaucoma progression: results from the Early Manifest Glaucoma Trial. Arch Ophthalmol 2002;120:1268-79.

7 Anderson DR, Normal Tension Glaucoma Study. Collaborative normal tension glaucoma study. Curr Opin Ophthalmology 2003;14:86-90.

8 Toris CB, Gabelt BT, Kaufman PL. Update on the mechanism of action of topical prostaglandins for intraocular pressure reduction. Surv Ophthalmol 2008;53(Suppl 1):S107-20.

9 Woodward DF, Krauss AH, Nilsson SF. Bimatoprost effects on aqueous humor dynamics in monkeys. J Ophthalmol 2010;2010:926192.

10 Gulati $\mathrm{V}$, Fan $\mathrm{S}$, Zhao $\mathrm{M}$, et al. Diurnal and nocturnal variations in aqueous humor dynamics of patients with ocular hypertension undergoing medical therapy. Arch Ophthalmol 2012;130:677-84.

11 Yamane S, Karakawa T, Nakayama S, et al. IOP-lowering effect of ONO-9054, a novel dual agonist of prostanoid EP3 and FP receptors, in monkeys. Invest Ophthalmol Vis Sci 2015;56:2547-52.

12 Karakawa T, Yamane S, Nagai K, et al. Effect of ONO-9054 on aqueous humor dynamics in monkeys. Invest Ophthalmol Vis Sci 2015;56:1974.

13 Suto F, Rowe-Rendleman CL, Ouchi T, et al. A novel dual agonist of EP3 and FP receptors for OAG and OHT: Safety, Pharmacokinetics and Pharmacodynamics of ONO-9054 in healthy volunteers. Invest Ophthalmol Vis Sci 2015;56:7963-70.

14 Berlin MS, Rowe-Rendleman C, Ahmed I, et al. EP3/FP dual receptor agonist ONO-9054 administered morning or evening to patients with open-angle glaucoma or ocular hypertension: results of a randomised crossover study. $\mathrm{Br} J \mathrm{Ophtha/mol}$ 2016;100:843-7.

15 Harris A, Ward CL, Rowe-Rendleman CL, et al. Ocular Hypotensive Effect of ONO9054, an EP3/FP Receptor Agonist: Results of a Randomized, Placebo-controlled, Dose Escalation Study. J Glaucoma doi:10.1097/IJG.0000000000000449

16 Golan S, Rosenfeld E, Shemesh G, et al. Original and generic latanoprost for the treatment of glaucoma and ocular hypertension: are they really the same? Clin Exp Pharmacol Physiol. 2015;42:220-4.

17 Narayanaswamy A, Neog A, Baskaran M, et al. A randomized, crossover, open labe pilot study to evaluate the efficacy and safety of Xalatan in comparison with generic Latanoprost (Latoprost) in subjects with primary open angle glaucoma or ocular hypertension. Indian I Ophthalmol 2007;55:127-31.

18 Hedman K, Alm A. A pooled data analysis of three randomised, double-masked six-month clinical studies comparing the intraocular pressure reducing effect of latanoprost and timolol. Eur J Ophthalmology 2000;10:95-104.

19 Bacharach J, Dubiner HB, Levy B, et al. Double-masked, randomized, dose-response study of AR-13324 versus latanoprost in patients with elevated intraoculat pressure. Ophthalmology 2015;122:302-7.

20 Parrish RK, Palmberg P, Sheu WP, XLT Study Group. A comparison of latanoprost, bimatoprost, and travoprost in patients with elevated intraocular pressure: a 12-week, randomized, masked-evaluator multicenter study. Am I Ophthalmol 2003;135:688-703.

21 Weinreb RN, Ong T, Sforzolini B, et al. A randomised, controlled comparison of latanoprostene bunod and latanoprost $0.005 \%$ in the treatment of ocular hypertension and open angle glaucoma: the VOYAGER study. Br I Ophthalmol 2015;99:738-45.

22 Camras CB, Alm A, Watson P, et al. Latanoprost, a prostaglandin analog, for glaucoma therapy. Efficacy and safety after 1 year of treatment in 198 patients. Latanoprost Study Groups. Ophthalmology 1996;103:1916-24. 